\title{
Algumas considerações sobre a questão do suicídio na filosofia de Arthur Schopenhauer
}

\author{
Élcio José dos Santos \\ Mestrando em Filosofia pela UFPR
}

Para Viviane

RESUMO: O objetivo do presente texto é abordar algumas questões referentes à posição de Schopenhauer acerca do suicídio. Se viver é sofrer, somente a dor é positiva, vida e morte são meras ilusões. Se o mundo constitui o inferno, seria o suicídio a forma mais eficiente de escapar ao martírio da vida? De acordo com o filósofo, não. O suicídio não passa de um equívoco, pois ao destruir o corpo o indivíduo não nega a Vontade, mas a afirma, sendo que o corpo é apenas o fenômeno dessa Vontade. No entanto, também não há motivos para o suicídio ser considerado um crime. A moral utilizada pelos filósofos europeus não tem bases para condená-lo, mas somente a partir de um ponto de vista ascético é que podemos entender porque é errado matar a si próprio.

PALAVRAS-CHAVE: Suicídio; Sofrimento; Ascetismo.

ABSTRACT: The purpose of this text is to address certain issues regarding the position of Schopenhauer about suicide. If life is suffering, only the pain is positive, life and death are mere illusions, if "the world is a hell," would be suicide the most efficient way to escape the martyrdom of life? According to the philosopher, don't, suicide is just a mistake, because destroying the body does not negate the individual's Will, but corroborate it, because the body is only the phenomenon of the Will. But there is no reason to consider suicide a crime, the morality used by European philosophers have no basis to condemnate it, but only from an ascetic point of view we can understand because it's wrong to kill himself.

KEYWORDS: Suicide; Suffering; Asceticism.

Só existe um problema filosófico realmente sério: é o suicídio. Julgar se a vida vale ou não vale a pena ser vivida é responder à questão fundamental da filosofia. O resto, se o mundo tem três dimensões, se o espirito tem nove ou doze categorias, aparece em seguida.

Albert Camus ${ }^{1}$

\section{O pesadelo da existência e o sofrimento do mundo}

Se o sentido mais próximo e imediato de nossa vida não é o sofrimento, nossa existência é o maior contra-senso do mundo. Pois constitui um absurdo supor que a dor infinita, originária da necessidade essencial à vida, de que o mundo está pleno, é sem sentido e puramente acidental. Nossa receptividade para a dor é quase infinita, aquela para o prazer possui limites estreitos. Embora toda infelicidade individual apareça como exceção, a infelicidade em geral constitui a regra. ${ }^{2}$

${ }^{1}$ CAMUS, Albert. O mito de Sísifo, p. 17.

2 SCHOPENHAUER, A. P, "Contribuições à Doutrina do Sofrimento do mundo", §148, p. 277. 
Em sua obra magna, $O$ Mundo Como Vontade e como Representação, Schopenhauer desenvolve uma rica argumentação acerca da condição do homem no mundo, de uma forma radicalmente oposta aos filósofos tidos como otimistas (como, por exemplo, Leibniz). Para Schopenhauer, a Vontade ${ }^{3}$ é a precursora de todo o sofrimento do ser humano, é desejo cego, irresistivel, tal como a vemos mostrar-se no mundo bruto, na natureza vegetal e suas leis e o que ela quer é sempre a vida, isto é, a pura manifestação dessa vontade. O mundo tal qual nos é apresentado fenomenicamente nada mais é que a objetivação dessa Vontade ${ }^{4}$ regida pelo princípio de individuação e pelo de razão suficiente. O primeiro princípio é compreendido pelo espaço e tempo, que permitem a pluralidade dos fenômenos e a sua sucessão; o segundo é o princípio de razão, que aparece também como lei de causalidade ${ }^{5}$, e explica porque os fenômenos dados na representação se manifestam de uma determinada maneira e não de outra.

Enquanto fenômeno - objetivação da Vontade - o indivíduo deseja e, por desejar (no sentido de buscar por algo), sofre. Todo desejo é condição preliminar de todo prazer e tal desejo só pode advir de uma privação, uma vez que não é possível desejar aquilo que já temos. Quando não obtemos algo que desejamos, sofremos, e todo sofrimento pode ser considerado uma dor. Béziau ${ }^{6}$ nos explica que, para Schopenhauer, enquanto coisa em si a Vontade é una e indestrutível, mas ao se objetivar no homem e na natureza ela se faz múltipla. Se cada objetivação particular também precisa se afirmar, o fará negando as demais, em outras palavras, o mundo fenomênico pode ser considerado uma verdadeira arena de batalha entre fenômenos particulares que tentam se afirmar enquanto parte da Vontade. Schopenhauer nos mostra que é a partir dessa individuação que surge o egoísmo. Quando afirmamos nosso apego ao corpo de que somos dotados, quando afirmamos nossa

\footnotetext{
${ }^{3}$ Utilizo "Vontade" com a primeira letra em maiúscula para efeito de distinção entre o simples ato volitivo de um sujeito particular e o impulso cego, que anima o mundo.

${ }^{4}$ SCHOPENHAUER, A. MVR I, §54, p. 359.

${ }^{5}$ Schopenhauer adota a forma já empregada por Wolff: nihil est sine ratione, cur potius sit quam non sit (nada é sem razão de ser ou não ser). Se encontra explicado de forma bastante detalhada em sua dissertação Sobre a quádrupla raiz do princípio de razão suficiente, §20: "I call it the Principle of Sufficient Reason of Becoming, principius rationis sufficientis fiendi. By it,all the objects presenting themselves within the entire range of our representation are linked together, as far as the appearance and disappearance of their states are concerned, i.e. in the movement of the current of Time, to form the complex of empirical reality". [Eu o chamo Principio de Razão Suficiente do Devir, principius rationis sufficientis fiendi. Por ele todos os objetos situados no campo de nossas representação total estão ligados, tanto na aparição quanto no ocultamento, em causa, isto é, na direção do correr do Tempo, à forma do complexo de realidade empírica.] - Tradução minha.

${ }^{6}$ BÉZIAU, J-Y. “O suicídio segundo Arthur Schopenhauer”, in Discurso, n²8, 1997, p. 129.
} 
vontade, nos isolamos dos outros, e essa é uma atitude egoísta ocasionada pela ilusão da individuação. ${ }^{7} \mathrm{O}$ sujeito acredita ser uno e distinto dos demais em sua essência, mas sua natureza pertence à mesma origem de todas as coisas que se apresentam no mundo, ou seja, é apenas uma ínfima parte da Vontade.

Trabalho, aflição, esforço e necessidade constituem durante toda a vida a sorte da maioria das pessoas. Porém se todos os desejos, apenas originados, já estivessem resolvidos, o que preencheria então a vida humana, com que se gastaria o tempo? Que se transfira o homem para um país utópico, em que tudo crescesse sem ser plantado, as pombas revoassem já assadas, e cada um encontrasse logo e sem dificuldade a sua bem-amada. Ali em parte os homens morrerão de tédio ou se enforcarão, em parte promoverão guerras, massacres e assassinatos, para assim se proporcionar mais sofrimento do que o posto pela natureza. Portanto, para uma tal espécie, como a humana, nenhum outro palco se presta, nenhuma outra existência. ${ }^{8}$

$\mathrm{Na}$ visão do filósofo, o ser humano é um animal volitivo por excelência ${ }^{9}$ e está inevitavelmente fadado ao sofrimento, visto que a felicidade (...) é realmente e na sua essência apenas algo de negativo; nela não há nada de positivo, pois a satisfação tem de ser a satisfação de um desejo ou término de uma dor, e o desejo (privação) é a condição preliminar de todo prazer. Ora com a satisfação cessa o desejo, e, por consequência, também o prazer. ${ }^{10}$ Como a Vontade é impulso cego e, ao mesmo tempo, autofágica, os desejos só podem cessar por um breve período de tempo, donde sobrevém o tédio e, tão logo cesse o tédio, o indivíduo volta a querer e, consequentemente, a sofrer. Nas palavras de Schopenhauer: a vida oscila como um pêndulo, para aqui e para acolá, entre a dor e o tédio, os quais em realidade são seus componentes básicos. ${ }^{11}$

Segundo Schopenhauer, a solução para o problema do sofrimento seria enxergá-lo tal como os homens santos e, através da vontade de afirmação do eu individual, tomar consciência da ilusão da individuação, compartilhando da dor do mundo inteiro. Ao compreender que a individuação é apenas uma ilusão e que somente a negação da Vontade de vida pode pôr termo à dor e ao sofrimento, o homem se torna livre. Um indivíduo que

7 SCHOPENHAUER, A. MVR I, §65, p. 462.

8 SCHOPENHAUER, A. P, "Contribuições à Doutrina do Sofrimento do mundo", §152, p. 279.

9 SCHOPENHAUER, A. MVR I, §57, p. 401.

10 SCHOPENHAUER, A. MVR I, §58, p. 411.

${ }^{11}$ SCHOPENHAUER, A. MVR I, §57, p. 402. 
alcance tal estado de consciência, por mais pobre, destituído de alegria e cheio de privação que seja o seu estado quando visto de fora, é, no entanto cheia de alegria interior e verdadeira paz celestial. ${ }^{12}$

\section{Suicídio x Ascese}

Diante de tantos horrores e da perspectiva de um destino que pode guardar doenças, perseguições, empobrecimento, fome, morte, mutilação, cegueira, loucura, dentre outras desgraças, uma alternativa que surge à mente do indivíduo é o suicídio. Em $O$ Mundo Schopenhauer nos apresenta sua teoria sobre o suicídio no $\S 69$, retoma ainda essa temática nos capítulos V e VII de Sobre o Fundamento da Moral, e no capítulo 13 da obra Parerga e Paralipomena. Em O Mundo, se preocupa principalmente em nos esclarecer os aspectos fundamentais de seu sistema filosófico relacionando os temas entre si e, portanto, temos um texto mais técnico e ligado ao restante da obra. Na obra Sobre o Fundamento da Moral preocupa-se basicamente em contrapor seu sistema ético ao de Kant, resultando em uma abordagem mais breve e de caráter eminentemente crítico. Parerga e Paralipomena constituem seu trabalho mais maduro, pode-se notar um estilo mais elegante e independente, e no ensaio intitulado Sobre o Suicídio Schopenhauer ao defender o direito daquele que sofre de se libertar do sofrimento através do auto-homicídio, parece estar de acordo que o suicídio pode ser uma real alternativa para quem já chegou ao limite da dor.

Para o pensador, a vida já tem seu destino traçado: a morte; esta é a mais segura certeza que podemos ter com relação ao destino de nossas vidas. Compara a vida a uma bolha de sabão, que sopramos animadamente apesar de ter a certeza de que irá estourar. ${ }^{13} \mathrm{O}$ suicídio apresenta-se como um remédio para a doença que é a vida mas, para Schopenhauer, como tentativa de negação da vontade é inútil e tolo, ${ }^{14}$ pois o real objetivo do suicida é pôr fim ao sofrimento, já que se pudesse viver de outro modo, assim o faria. É praticamente impossível alguém pôr fim à própria vida se não estiver diante de uma situação considerada insuportável e sem saída, todavia, o suicídio não pode ser solução para coisa alguma, pois a morte não é um aniquilamento absoluto, mas um último ato de

\footnotetext{
${ }^{12}$ SCHOPENHAUER, A. MVR I, §68, p. 494.

${ }^{13}$ SCHOPENHAUER, A. MVR I, § 57, p. 401.

${ }^{14}$ SCHOPENHAUER, A. MVR I, §69, p. 504.
} 
vigorosa afirmação da Vontade $^{15}$, a qual o suicida acredita estar destruindo juntamente com seu corpo, mas permanece intacta. Segundo Schopenhauer, aí reside o erro do suicida: ele toma o fenômeno pela coisa-em-si.

Precisamente porque o suicida não pode cessar de querer, cessa de viver. A Vontade se afirma aqui pela supressão do seu fenômeno, pois não pode afirmar-se de outro modo. (...) O sofrimento se aproxima e, enquanto tal, abre-lhe a possibilidade de negação da Vontade, porém ele a rejeita ao destruir o fenômeno da Vontade, o corpo, de tal forma que a Vontade permanece inquebrantável. - Eis por que todas as éticas, tanto filosóficas quanto religiosas, condenam o suicídio, embora elas mesmas nada possam oferecer senão estranhos argumentos sofísticos. ${ }^{16}$

Para Schopenhauer, tais argumentos sofísticos não possuem força alguma sobre um indivíduo desejoso de pôr fim à própria vida. Ao fazer alusão às razões que Kant apresenta contra o suicídio ele nos diz: Temos de rir quando pensamos que tais reflexões teriam de arrancar o punhal das mãos de Catão, de Cleópatra, de Cócio Nerva (Tacitus, Anais 6, 26) ou de Arria de Paetos (Plínio, Epístolas 3, 16). ${ }^{17}$

Parece haver ainda um segundo caminho para o suicídio: aquele advindo da negação da Vontade. Neste, a ascese atinge grau tão elevado onde "falta até mesmo a vontade necessária para a conservação da vida vegetativa do corpo por ingestão de alimento”, o indivíduo morre, mas permanece o puro sujeito do conhecimento. Tal ato é raro e se consuma somente por meio do asceta que, já por inteiro resignado, cessar de viver, simplesmente porque cessou por inteiro de querer. ${ }^{18}$ Schopenhauer, não chama em sua obra tal ato de "suicídio", mas vê nele a única maneira do indivíduo alcançar a redenção. Todavia, é possível objetar que estando o asceta consciente de seu ato e das conseqüências que dele podem advir - a saber, a morte como preço de sua redenção - ele comete o único verdadeiro suicídio.

\section{O suicídio como direito do ser humano}

\footnotetext{
${ }^{15}$ SCHOPENHAUER, A. Metafisica de las costumbres, p. 185.

${ }^{16}$ SCHOPENHAUER, A. MVR, §69, p. 505.

${ }^{17}$ SCHOPENHAUER, A. MVR, § 5, p. 32.

${ }^{18}$ SCHOPENHAUER, A. MVR, §69, p. 507.
} 
Só ao homem que não é, tal como o animal, limitado ao presente e deixado apenas à mercê do sofrimento corporal, mas a um sofrimento incomparavelmente maior, o espiritual, tomado de empréstimo ao futuro e ao passado, a Natureza concedeu, como compensação, a prerrogativa de poder pôr um termo à sua vida quando lhe aprouver, mesmo antes que ela lhe estabeleça um alvo e, portanto, a prerrogativa de viver não como um animal, enquanto possa, mas também só enquanto queira. ${ }^{19}$

Segundo Schopenhauer, o animal tem a vantagem sobre o homem de viver somente no presente, ou seja, não sente remorso por suas ações nem é assombrado pela consciência de sofrimentos vindouros e da morte certa e, por isso, sofre certamente muito mais de forma física. O homem, por outro lado, sofre ao se recordar dos sofrimentos passados e em pensar naqueles que ainda virá a sofrer, isto é, ele é capaz de sofrer duplamente, pois sofre também espiritualmente. Mas de acordo com o filósofo, ao homem foi concedido o poder de decidir o quanto quer viver e quando morrer, o que equivaleria a um presente funesto. Schopenhauer parece compartilhar da opinião de Plínio: que também Deus não pode tudo; pois ele não pode, mesmo se ele quisesse decretar a sua morte, o que ele concedeu ao homem como seu melhor dom, por meio de tantos sofrimentos da vida, etc. ${ }^{20}$

Schopenhauer assegura no início do seu ensaio sobre o suicídio que são apenas os adeptos das religiões monoteístas, isso é, semíticas, que consideram o suicídio como um crime, o que é de se admirar, segundo ele, pois nem no Velho nem no Novo Testamento há alguma proibição, tampouco uma resoluta desaprovação do mesmo, podendo-se inferir que considerar o suicídio como crime com base na Bíblia é algo sem fundamento. Ele vai ainda mais longe e afirma que cada qual a nada mais no mundo tem um tão indiscutível direito quanto à sua própria pessoa e vida e, por isso, não tem sentido dizer que o suicídio é injusto ${ }^{21}$.

O filósofo de Dantzig condena a atitude da plebéia e beata Inglaterra quando, ao considerar o suicídio como um crime, confisca o espólio do morto e lhe concede um funeral vergonhoso. Schopenhauer faz um elogio, um pouco adiante no mesmo ensaio, a David Hume:

19 SCHOPENHAUER, A. M, § 5, p.32.

20 PLÍNIO, o Antigo. Apud: SCHOPENHAUER, A. Sobre o Suicídio, in Os Filósofos e o Suicídio. Grifo meu.

21 SCHOPENHAUER, A. Sobre o Suicídio, p. 149. 
As razões contra o suicídio, contudo, as quais são fornecidas pelo clero das religiões monoteístas, isto é, semíticas, e pelos filósofos que compartilham dessas razões, são fracas, sofismas fáceis de refutar. A mais profunda refutação delas foi apresentada por Hume em seu "Essay on Suicide”, que, apenas publicado depois de sua morte, de imediato foi suprimido na Inglaterra pela injuriosa beatice e pelo ignominioso poder dos padres; por isso, somente muitos poucos exemplares foram vendidos $(\ldots)^{22}$

No referido ensaio, Hume se propõe a provar que o suicídio não é uma transgressão de nosso dever para com Deus, para tal, o pensador examina os fatos a partir de uma visão cética e no âmbito da Natureza simplesmente. Para ele, no governo do mundo material Deus estabeleceu leis gerais e imutáveis, pelas quais todos os corpos, do maior planeta à menor partícula da matéria são mantidos em sua esfera e função próprias ${ }^{23}$ e no governo do mundo animal dotou todas as criaturas vivas de poderes fisicos e mentais, de sentidos, paixões, apetites, memória e juízo, pelos quais são regulados ou impelidos ao curso da vida a que se destinam, ${ }^{24}$ sendo através dessas leis gerais que Deus a tudo governa. Uma vez que a tudo criou e concedeu capacidades especiais às criaturas vivas, Hume afirma que todos os eventos (...) podem ser ditos ações do Todo Poderoso e todos os eventos são igualmente importantes aos olhos daquele ser infinito ${ }^{25}$ donde se segue que ao cometer suicídio, uma vez que o homem não usa senão as capacidades que Deus lhe concedeu, ele não pode incorrer em seu desagrado, pois não há ser algum que possua um poder ou faculdade que não tenha recebido de seu criador, nem um ser que, por uma ação, por irregular que ela seja, possa infringir o plano de sua providência. ${ }^{26}$

Assim, tendo em vista que a providência guiou todas essas causas, e nada ocorre no universo sem o seu consentimento e cooperação, então minha morte voluntária não acontece sem o seu consentimento, ${ }^{27}$ uma vez que se incorro no desagrado divino por tirar a minha vida, também incorreria em desagrado ao me desviar de uma árvore que desaba, ou construir casas ou navegar no oceano, pois essas ações visam preservar a minha vida e minha saúde, e, assim, tanto em um caso como em outro, modifico o curso original da

\footnotetext{
${ }^{22}$ SCHOPENHAUER, A. Sobre o Suicídio, p. 153.

${ }^{23}$ HUME, D. Do Suicídio, p. 111.

${ }^{24}$ HUME, D. Do Suicídio, p. 111.

${ }^{25}$ HUME, D. Do Suicídio, p. 112.

${ }^{26}$ HUME, D. Do Suicídio, p. 116.

${ }^{27}$ HUME, D. Do Suicídio, p. 117.
} 
natureza. Elas [as ações humanas] são todas, portanto, igualmente inocentes ou igualmente criminosas.

Hume também acredita que nenhum homem jamais jogou fora a sua vida enquanto valia a pena mantê-la, e, mais adiante no texto, conclui sua argumentação dizendo que se o suicídio não for um crime ambas, a prudência e a coragem, deveriam nos envolver em nossa liberação sumária da existência, quando ela se torna um fardo. ${ }^{28}$

De acordo com Schopenhauer, que um tratado puramente filosófico, que com fria razão refuta os motivos correntes contra o suicídio (...) tenha existido secreta e furtivamente (...) mostra quão boa consciência a Igreja possui sobre esse ponto. ${ }^{29}$ Nosso pensador condena a argumentação oferecida pelo clérigo contra o suicídio pois, segundo ele, apresentou no Mundo a única razão moral justa contra o suicídio, que está contida no fato de que suicídio opõe-se à obtenção do maior objetivo moral na medida em que ele substitui uma efetiva libertação deste lamentável mundo por uma libertação aparente, ${ }^{30}$ mas há, em sua opinião, um caminho muito longo entre considerar um erro se suicidar acreditando numa falsa libertação e taxar o suicídio de crime.

No final do $\S 69$ do Mundo Schopenhauer admite, contudo, que a questão do suicídio é difícil de explicar, principalmente a diferença entre essa morte voluntária resultante do extremo da ascese e aquela comum resultante do desespero, ${ }^{31}$ pois é possível que haja muitos graus diferentes e combinações possíveis entre os motivos capazes de levar o ser humano a suicidar-se.

\section{O que podemos esperar}

Diante das inúmeras desgraças que o mundo abriga e da morte certa, angústia e desespero são reações comuns do ser humano. Mas para Schopenhauer nada disso justifica o suicídio, que é apenas uma pseudo-libertação. O produto do suicídio frente ao desespero difere enormemente daquele obtido pelo asceta: enquanto o santo passa através do véu de Maya e alcança o conhecimento da verdade do mundo, o suicida permanece na ignorância e

\footnotetext{
${ }^{28}$ HUME, D. Do Suicídio, p. 121.

${ }^{29}$ SCHOPENHAUER, A. Sobre o Suicídio, p. 153.

${ }^{30}$ SCHOPENHAUER, A. Sobre o Suicídio, p. 153.

${ }^{31}$ SCHOPENHAUER, A. MVR I, § 69, p. 508.
} 
seu sofrimento não encontra fim na morte. ${ }^{32}$ Ademais, o suicídio é um ato fútil, uma vez que não soluciona o real problema, é expressão do mais extremo egoísmo e falta de empatia para com o próximo ${ }^{33}$.

Schopenhauer defende o direito ao suicídio como uma eutanásia, mas alerta o agente para o fato de que somente pela via do ascetismo encontrará a paz que tanto busca. Mas se o suicídio não soluciona o problema da existência, e a vida é uma mercadoria ruim, um pesadelo, um verdadeiro inferno onde o homem é o diabo do outro, seria a felicidade uma quimera? Para o pensador, sim. Porem isso não implica que não se possa viver bem. Nos Aforismos Para a Sabedoria de Vida o filósofo oferece uma série de alternativas para se contornar o problema do sofrimento, dentre eles se destacando a prudência e a serenidade, de modo a se viver da melhor forma possível, não da mais desejável: $O$ prudente aspira não ao prazer, mas à ausência de dor. ${ }^{34}$

\section{Referências bibliográficas}

CAMUS, Albert. O mito de Sísifo. Tradução de Ari Roitman e Paulina Watch. - $6^{\text {a }}$ edição Rio de Janeiro: Record, 2008.

BÉZIAU, Jean-Yves. "O suicídio segundo Arthur Schopenhauer”, in Revista Discurso, n'28, 1997: p. 128-143.

HUME, D. "Do Suicídio", in Os Filósofos e o Suicídio. Trad. de Lívia Guimarães. Organização de Fernando Rey Puente. Belo Horizonte: Editora UFMG, 2008.

SCHOPENHAUER, A. Aforismos Para a Sabedoria de Vida. Tradução de Jair Barboza. São Paulo: Martins Fontes, 2002.

- O mundo como Vontade e como Representação. Tradução: Jair Barboza. São Paulo: Editora UNESP, 2005.

- Metafísica de las Costumbres. Tradução de Roberto Rodriguez Aramayo. Madrid: Editorial Trotta, 2001.

. On The Fourfold Root of the Principle of Sufficient Reason. Trad. de

Karl Hillebrand. London: Cosimo Books, 2007.

${ }^{32}$ YOUNG, J. Schopenhauer, p.194.

${ }^{33}$ YOUNG, J. Schopenhauer, p. 195.

${ }^{34}$ SCHOPENHAUER, A. Aforismos para a sabedoria de vida, p. 140. 
. Parerga e Paralipomena ("Contribuições à Doutrina do Sofrimento do mundo"), in Vol. Schopenhauer, Col. Os Pensadores. Trad. de Wolgfgang Leo Maar. São Paulo: Nova Cultural, 1999.

Sobre o Fundamento da Moral. Trad. de Maria Lúcia Mello Oliveira Cacciola. São Paulo: Martins Fontes, 2001.

. Sobre o Suicídio. in Os Filósofos e o Suicídio. Trad. de Fernando Rey Puente. Organização de Fernando Rey Puente. Belo Horizonte: Editora UFMG, 2008.

YOUNG, Julian. Schopenhauer. New York: Routlegde, 2005.

Recebido: 08/10/10

Received: 10/08/10

Aprovado: 27/11/10

Approved: 11/27/10 